\title{
XX. On permanent magnet circuits
}

\section{George Hookham M.A.}

To cite this article: George Hookham M.A. (1889) XX. On permanent magnet circuits , Philosophical Magazine Series 5, 27:165, 186-189, DOI: 10.1080/14786448908628332

To link to this article: http://dx.doi.org/10.1080/14786448908628332

$$
\text { 册 Published online: } 29 \text { Apr } 2009 .
$$

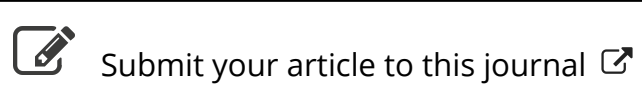

\footnotetext{
Џll Article views: 2
}

Q View related articles $\square$

4 Citing articles: 1 View citing articles 4 


\section{Mr. G. Hookham on Permanent Magnet Circuits.}

Sir William Thomson, in a paper on units of measurement, contemplates a time when many of the units we now employ will become things of the past by the introduction of the universal gravitation method of connecting mass with length and force.

The naming of particular units employed for a time in the process of this development cannot but retard its progress, and the unity of science should take place independently of the subdivisions which may exist to-day.

It is highly probable that chemical science may soon require a modification of our present units, and we must not keep combining weights, atomic heat, and so on, uncorrelated with the rest of the body of science because the development of science has taken the order it has done. It might have been quite otherwise.

Dr. Whewell entertained a speculation as to whether the laws of motion would ever have been discovered by an intellectual race of jelly-fish inhabiting a world in which were no solid bodies.

In like manner we may imagine that had Torpedoes, or other animals armed with a controllable electrical equipment, won the race for supremacy against man, the laws of electricity might have been reached before the mechanical laws. Faraday and Maxwell would have preceded Galileo and Newton, and Gymnotus might have exhibited in submarine air-cases that uncanny biped Homo who could give you a curious and mysterious shock with a stick or a stone.

\section{On Permanent Magnet Circuits. $B y$ George Hookham, M.A.*}

THE immediate object of my experiments in permanent magnets was a practical one, viz. to obtain a magnetic field suitable for the electromotor part of my electricity-meter. If by their use a constant field of sufficient intensity could be produced, its advantage in point of economy in use would make it of the greatest value. At the same time I was aware that the scientific world did not consciously believe in the possibility of a really constant permanent magnet, except when the magnetic circuit was complete through a magnetic metal.

But it occurred to me that there is one familiar case in which absolute constancy is admitted, and yet this condition is not fulfilled. I refer to the arrangement in which a soft iron ring is cut at two points diametrically opposite, and the

* Communicated by the Author, having been read before the Birmingham Philosophical Society, November 8, 1888. 
ends carefully refitted by filing and scraping. If, now, this ring is once strongly magnetized by an electrical current, we obtain a powerful permanent magnet. The magnetic circuit, however, is anything but complete. There are two breaks in it ; very minute, no doubt, if their mere dimensions are taken into account; but recent experiments seem to show that, however carefully we may fit together surfaces of iron, there is still an easily measurable resistance which is greater than would be due to the dimensions of the air-space; that there is in fact, in addition, a surface-resistance. Such a resistance is the equivalent of a small current tending to reverse the magnetism of the iron. Now, what enables soft and pure iron to withstand this demagnetizing agency? Apparently nothing but the coercive force of the iron, small as it is. Once magnetized, the softest iron under any circumstances remains at ordinary temperatures a permanent magnet, however weak; and one can only suppose that it is in virtue of this very small coercive force that the soft iron magnet overcomes even the small resistance of well-fitted joints. If this supposition were well founded, I felt almost certain that when very hard magnets of tungsten steel were substituted for the soft iron, air-space resistances incomparably greater might be overcome; and yet the magnetic intensity in the circuit be very considerable, and to all intents and purposes absolutely constant. It was at any rate quite certain that this state of things would obtain, if the power of overcoming resistances in the circuit were at all proportional to the coercive force of the material of the magnets. My anticipations have been completely realized, and I have been able to construct magnets which are truly permanent.

As to the special arrangement, when the object in view, as in this case, is subject to commercial considerations, cost of production makes the use of straight bar-magnets almost imperative. A number of these are enclosed in a brass tube, to the ends of which are attached soft cast-iron arms, curving round towards the pole-pieces, which closely face each other, so as to form a narrow slit in which the thin disk-armature of the meter revolves. The magnetic resistance of the arms is practically negligible. As to proportions I was, in principle, guided by the analogy of the voltaic circuit. There, if wo wish to overcome a considerable external resistance, the plan is to pile up the electromotive force by increasing the number of cells in series, paying little regard to the consequent increase of internal resistance. Here the steel magnet-bars constitute the magnetic cell, whose magnetomotive force-to use what is at any rate a most convenient expression-is 
proportional to the length of the bars. Hence, in order to overcome a considerable air-space resistance, the actual dimensions must be such that the ratio of the total cross-section of the steel magnet-bars to their length must be very small compared with the ratio of the cross-section of the air-space to the distance between the pole-pieces. Obviously, too, the best proportions would depend on the nature of the steel magnets-an entirely unknown quantity-so that the first experiment had to be made almost at haphazard. Curiously enough $I$ have never been able to improve on the proportions used in this first experiment. I have had some fairly accurate tests made lately, and find that the best relation between the two ratios, as stated above, is about 1 to 70 . Thus, if A equal the area of cross-section of the air-space, $L$ the distance between the pole-pieces, $a$ the cross-section of the steel magnets, $l$ the length of the bars, then $\frac{\mathrm{A}}{\mathrm{L}}$ should equal about $70 \times \frac{a}{l}$. For example, if the cross-section of the steel magnets is 3 square inches, and their length 6 inches, then the air-space may be 9 square inches, and the pole-pieces $\frac{1}{4}$ inch apart, or $4 \frac{1}{2}$ square inches with $\frac{1}{8}$ inch distance, or $2 \frac{1}{4}$ square inches with $\frac{1}{16}$ inch, and so on, for in each case the relation remains the same, viz. $1: 72$.

The object of making such tests was to got the best possible return for a given weight of steel. On the analogy of the voltaic cell, this object would be attained when the internal and external resistances were equal. With the proportion at 1 to 70 my tests showed that this equality practically existed; and, consequently, that the resistance of tungsten steel, as I use it, is about one seventieth that of air, and therefore about twenty times that of soft iron. The actual intensity obtained is also very high, being in the ordinary pattern of my meter nearly 4000 in the air-space, or at least half that in the airspace of a modern dynamo, and represents a magnetizing force of 1000 ampere-turns on a soft-iron core of full sectional area.

Some very simple, but practically important, results follow from the assumed analogy to the voltaic cell. In indicating them I neglect the resistance of the cast iron in the circuit, as this can always be made negligible at a trifling extra cost. Thus we can increase the intensity in an air-space of constant area in the proportion of the square root of the weight of steel magnets. We can, for instance, double the intensity by doubling the length, and at the same time doubling the cross-section of the magnet-bars, for then the magnetomotive force is doubled, and all resistances remain the same. Again, we may double the intensity in the air-space by 
simply halving the area and halving the distance, for we shall then have made no change either in the magneto-motive force or the resistances, and, consequently, the same total induction is compressed into half the area; or, again, we may double the distance between the pole-pieces and preserve the same intensity by simply doubling the length of the magnets. It is, in fact, quite easy to design an arrangement of permanent magnets that shall, within obvious limits, produce any given intensity of magnetic field in any given area of cross-section of air-space. These conclusions have been to a great extent tested by practice, and so far as they go the analogy on which they are founded holds good. The analogy is, in fact, mutatis mutandis, one of universal application.

The current by which the circuit is magnetized is always applied when everything is in position; otherwise very small intensity results. The magnets are flashed by a current from a dynamo to practical saturation. The coils are then removed, and the magnets hammered severely. The hammering seldom reduces the intensity more than about one per cent. In months of continued testing I have never found any measurable fallingoff in the field of a magnet so treated. If a reversing current is applied, the intensity will spring up on removal of the current, and will sometimes continue to rise appreciably for a considerable period. After a time it would probably fall again; but, if the weakening under the reverse current has amounted to, say, twenty per cent., never to the lowest point then reached, and, perhaps, never to the point to which it springs at once, on the removal of the reverse current; and, further, I have little doubt that an experiment might be arranged in which magnetizing and demagnetizing currents should be applied alternately in such a manner that, on their cessation, the successive strengthenings and weakenings of the field would repeat themselves backwards, just as was the case with the windings and unwindings in Sir W. Thomson's experiments on the "Fatigue of Metals." If so, the latest experiments on torsion would but add another analogy to Wiedemann's famous list.

XXI. Note on M. Ph. Plantamour's Observations by means of Levels on the Periodic Movements of the Ground at Secheron, near Geneva. By CharLes Davison, M.A., Mathematical Master at King Edward's High School, Birmingham*.

BSERVATIONS on the movements of the ground by means of levels have recently been made by many

* Communicated by the Author. 